ISSN 2442-3041

Math Didactic: Jurnal Pendidikan Matematika

Vol. 1, No.1, Januari - April 2015

(c) STKIP PGRI Banjarmasin

\title{
MATEMATIKA HIJAU SEBAGAI SALAH SATU UPAYA PENDIDIKAN KARAKTER BERWAWASAN LINGKUNGAN ${ }^{4}$
}

\author{
Desy Arnita Dewi \\ MA Negeri 2 Banjarmasin \\ E-mail: des_arnita@yahoo.com
}

\begin{abstract}
Abstrak: Kerusakan lingkungan akhir-akhir ini semakin terasa dampaknya bagi masyarakat. Keterlibatan semua pihak diperlukan untuk mengendalikan dan memperbaikinya, termasuk keterlibatan pelaku pendidikan. Pembelajaran matematika di sekolah dituntut berpartisipasi dan berkontribusi dalam pembentukan nilai-nilai positif dalam diri siswa. Nilai-nilai positif yang dimaksud adalah nilai peduli terhadap upaya perlindungan dan pelestarian lingkungan hidup. Artikel ini menguraikan terlebih dahulu tujuan dan fungsi pembelajaran matematika di sekolah, kemudian dikaitkan dengan perannya dalam pembentukan karakter berwawasan lingkungan. Pendidikan lingkungan hidup yang diintegrasikan dalam pembelajaran matematika ini disebut sebagai pembelajaran matematika hijau. Peran guru sangat penting sebagai subjek atau pelaku pendidikan di sekolah. Peran guru tersebut adalah dalam hal mengembangkan konsep dan contoh permasalahan dalam pembelajaran matematika yang dikaitkan dengan isu lingkungan. Tujuannya adalah selain siswa menguasi matematika juga tertanamnya nilai-nilai pelestarian lingkungan hidup dalam diri siswa sehingga akan membawa manfaat bagi kesejahteraan umat manusia.
\end{abstract}

Kata Kunci : matematika hijau, pendidikan karakter, pelestarian lingkungan

Kerusakan lingkungan hidup akhir-akhir ini sudah semakin parah, hal ini ditandai dengan seringnya peristiwa bencana alam menghiasi pemberitaan baik di media cetak ataupun media elektronik. Kebakaran hutan, tanah longsor, musibah banjir, dan isu-isu lingkungan lain sebagian besar disebabkan oleh ulah tangan manusia. Perilaku hidup manusia yang lalai, egois dan tidak bertanggung jawab dalam mengeksploitasi lingkungannya termasuk sering diabaikannya kepentingan pelestarian lingkungan hidup di tingkat pengambil keputusan menandakan adanya masalah degradasi moral. Moral yang buruk mengakibatkan kondisi lingkungan hidup semakin kritis dan akhirnya merugikan manusia itu sendiri. Semua pihak diharapkan turut serta melakukan penyelamatan dan pelestarian lingkungan hidup dengan mengembangkan sikap, bentuk-bentuk perilaku, kemampuan sosial dan kemampuan individu yang mencintai lingkungan. Pendidikan sangat mempengaruhi perkembangan fisik, daya jiwa (akal, rasa dan

\footnotetext{
${ }^{4}$ Disampaikan pada Seminar Nasional Pendidikan Matematika STKIP PGRI Banjarmasin, 28 Januari 2015
} 
kehendak), sosial dan moralitas manusia serta merupakan alat terpenting untuk menjaga diri dan memelihara nilai-nilai positif, termasuk nilai berwawasan lingkungan. Tentunya dengan pengaruh yang ditimbulkan pendidikan ini memberikan dampak pada bertambahnya pengetahuan dan keterampilan peserta didik serta akan menolong dalam pembentukan sikap konstruktif dalam memanfaatkan lingkungan dan sumber daya alam. Melalui lembaga-lembaga pendidikan yang dengan sengaja mentransformasikan warisan budayanya, yaitu pengetahuan, nilainilai dan keterampilan-keterampilan dari generasi ke generasi maka diharapkan akan terbentuk nilai-nilai positif siswa termasuk sikap mencintai dan sadar akan pengendalian dan pelestarian lingkungan hidup.

Sejalan dengan diprogramkannya sekolah-sekolah adiwiyata baik tingkat kabupaten, provinsi, nasional bahkan adiwiyata mandiri yang bertujuan mewujudkan warga sekolah yang bertanggungjawab dalam perlindungan dan pelestarian lingkungan hidup maka salah satu cara adalah dengan mengintegrasikan pendidikan lingkungan hidup ke dalam pembelajaran di kelas. Matematika sebagai bagian dari kurikulum di sekolah juga dapat berperan menanamkan nilai-nilai berwawasan lingkungan tersebut kepada warga sekolah melalui implementasinya dalam pembelajaran baik pada aspek pengetahuan (kognitif), kesadaran atau kemauan (afektif), dan tindakan (psikomotor).

Karena itulah, sebagai bagian yang terintegrasi dengan kurikulum sekolah dan ada disetiap jenjang pendidikan, maka mata pelajaran ini dapat berpartisipasi dan berkontribusi dalam pembentukan karakter berwawasan lingkungan. Artikel singkat ini bertujuan untuk menguraikan bagaimana pembelajaran matematika dapat membentuk karakter yang berwawasan lingkungan.

\section{Tujuan dan Fungsi Pembelajaran Matematika di Sekolah}

Sebagai salah satu bagian yang terintegrasi dalam kurikulum sekolah sudah seharusnya matematika memberikan kontribusi dalam pembentukan karakter bangsa, baik secara langsung atau pun tidak langsung. Berdasarkan kurikulum nasional, tujuan umum diberikannya matematika pada jenjang pendidikan dasar dan menengah meliputi dua hal, yaitu :

1. Mempersiapkan siswa agar sanggup menghadapi perubahan keadaan di dalam kehidupan dan di dunia yang selalu berkembang, melalui latihan bertindak atas dasar pemikiran secara logis, rasional, kritis, cermat, jujur, efektif dan efisien.

2. Mempersiapkan siswa agar dapat menggunakan matematika dan pola pikir matematika dalam kehidupan sehari-hari, dan dalam mempelajari ilmu pengetahuan.

Dari dua hal di atas dapat disimpulkan bahwa tujuan umum pertama, pembelajaran matematika pada jenjang pendidikan dasar dan menengah adalah memberikan penekanan pada penataan nalar dan pembentukan karakter peserta didik. Tujuan kedua memberikan penekanan pada keterampilan dalam penerapan matematika, baik dalam kehidupan sehari-hari maupun dalam membantu mempelajari ilmu pengetahuan lainnya.

Selanjutnya, fungsi mata pelajaran matematika adalah sebagai alat, pola pikir, dan ilmu atau pengetahuan. Ketiga fungsi matematika tersebut hendaknya dijadikan acuan dalam pembelajaran matematika sekolah. Dengan mengetahui fungsi-fungsi matematika tersebut diharapkan kita sebagai guru atau pengelola pendidikan dapat memahami adanya hubungan antara matematika dengan berbagai ilmu lain atau kehidupan. Sebagai tindak lanjutnya sangat diharapkan agar para siswa diberikan 
penjelasan atau contoh penggunaan matematika agar para siswa dapat memecahkan masalah dalam mata pelajaran lain, dalam kehidupan kerja atau dalam kehidupan sehari-hari. Namun tentunya harus disesuaikan dengan tingkat perkembangan siswa, sehingga diharapkan dapat membantu proses pembelajaran matematika di sekolah.

Siswa diberi pengalaman menggunakan matematika sebagai alat untuk memahami atau menyampaikan suatu informasi misalnya melalui persamaan-persamaan, atau tabeltabel dalam model-model matematika yang merupakan penyederhanaan dari soal-soal cerita atau soal-soal uraian matematika lainnya. Belajar matematika bagi para siswa, juga merupakan pembentukan pola pikir dalam pemahaman suatu pengertian maupun dalam penalaran suatu hubungan di antara pengertian-pengertian itu.

Dalam pembelajaran matematika, para siswa dibiasakan untuk memperoleh pemahaman melalui pengalaman tentang sifat-sifat yang dimiliki dan yang tidak dimiliki dari sekumpulan objek (abstraksi). Dengan pengamatan terhadap contoh-contoh dan bukan contoh diharapkan siswa mampu menangkap pengertian suatu konsep. Selanjutnya dengan abstraksi ini, siswa dilatih untuk membuat perkiraan, terkaan, atau kecenderungan berdasarkan kepada pengalaman atau pengetahuan yang dikembangkan melalui contoh-contoh khusus (generalisasi). Di dalam proses penalarannya dikembangkan pola pikir induktif maupun deduktif. Namun tentu kesemuanya itu harus disesuaikan dengan perkembangan kemampuan siswa, sehingga pada akhirnya akan sangat membantu kelancaran proses pembelajaran matematika di sekolah.

Fungsi matematika yang ketiga adalah sebagai ilmu atau pengetahuan, dan tentunya pengajaran matematika di sekolah harus diwarnai oleh fungsi yang ketiga ini. Kita sebagai guru harus mampu menunjukkan betapa matematika selalu mencari kebenaran, dan bersedia meralat kebenaran yang telah diterima, bila ditemukan kesempatan untuk mencoba mengembangkan penemuanpenemuan sepanjang mengikuti pola pikir yang sah.

Dari tujuan dan fungsi matematika tersebut di atas, kita sebagai guru disadarkan akan perannya sebagai motivator dan pembimbing siswa dalam pembelajaran matematika di sekolah sehingga proses yang dilalui dan konsep yang ditemui dalam pembelajaran matematika dapat dikembangkan sehingga membawa pengaruh positif dalam kehidupan siswa dan lingkungannya.

\section{Pendidikan Lingkungan Hidup melalui Pembelajaran Matematika Hijau}

Pendidikan lingkungan hidup adalah pendidikan yang menggunakan suatu pendekatan belajar "across the curriculum", artinya belajar yang membantu 4 sasaran didik untuk memahami lingkungan hidup dengan tujuan akhir agar mereka memiliki kepedulian untuk menjaga dan melestarikan lingkungan dan sikap bertanggung jawab dan memupuk keinginan serta memiliki keterampilan untuk melestarikan lingkungan agar dapat tercipta suatu sistem kehidupan bersama (Yusuf, 2000). Pendidikan lingkungan hidup yang diintegrasikan dalam pembelajaran matematika disebut sebagai Pembelajaran Matematika Hijau.

Frudental berpendapat bahwa dalam pembelajaran matematika perlu mengenal dengan baik apa itu matematika? bagaimana cara belajar matematika? dan bagaimana matematika harus diajarkan? Frudental juga mempunyai pandangan bahwa matematika adalah human activity dan pelajar bukan passive receivers of ready-made mathematics. Berdasar hal tersebut, maka pembelajaran matematika hijau dapat dimasukkan sebagai bagian pengembangan dari pendidikan matematika realistik dimana proses belajar 
mengajar matematika tidak terlepas dari lingkungan peserta didik (Streefland 1991).

Menurut Hobri (2009), karakteristik pendidikan matematika realistik antara lain menggunakan masalah kontekstual (the use of context), yaitu pembelajaran dimulai dengan menggunakan masalah kontekstual sebagai titik tolak atau titik awal untuk belajar. Masalah kontekstual yang menjadi topik pembelajaran harus merupakan masalah sederhana yang dikenali siswa. Dalam hal ini, isu-isu lingkungan bisa dijadikan sebagai masalah kontekstual untuk memulai pembelajaran.

Dengan demikian, pendidikan lingkungan hidup dapat diintegrasikan secara langsung dalam pembelajaran matematika. Interaksi belajar mengajar dalam pembelajaran Matematika Hijau diupayakan mengangkat contoh permasalahan yang berkaitan dengan pendidikan lingkungan hidup, sehingga siswa tidak merasa pendidikan lingkungan hidup itu terpisah dari pengajaran matematika.

\section{Implementasi Pembelajaran Matematika Hijau}

Salah satu pertanyaan yang paling menantang yang dihadapi seorang guru matematika adalah "Apa manfaat dari materi yang dipelajari?" Sayangnya, untuk beberapa topik seorang guru matematika hanya bisa menjawab dengan jawaban-jawaban umum, seperti mengindikasikan manfaat pada topik berikutnya yang akan dipelajari oleh siswa. Padahal, sebuah topik matematika bisa sangat kreatif dikembangkan oleh seorang guru dengan mengaitkannya pada hal-hal yang akan membangun pola pikir positif bagi siswa, termasuk menanamkan sikap peduli dan cinta lingkungan pada siswanya. Untuk memanamkan pembelajaran matematika berwawasan lingkungan maka perlu kreativitas guru mengaitkan topik yang dipelajari dengan contoh yang berkaitan dengan kelestarian lingkungan hidup.

Sebagai ilustrasi, topik Logika Matematika di kelas X SMA yang memberikan konsep tentang pernyataan majemuk implikasi dapat dikaitkan dengan permasalahan lingkungan, misalnya " jika membuang sampah sembarangan maka akan mengotori lingkungan" atau kalimat majemuk berkuantor seperti "jika banyak pohon ditebang maka akan ada daerah yang kebanjiran". Contoh lain, misalnya aplikasi dari prinsip silogisme berikut.

- Jika lingkungan kotor, maka banyak nyamuk berterbangan.

- Jika banyak nyamuk berterbangan, maka wabah penyakit mudah menyebar.

Jadi, ...

Dari kalimat di atas, maka kesimpulan yang sah adalah: "Jika lingkungan kotor, maka wabah penyakit mudah menyebar".

Terkait materi fungsi kuadrat, guru matematika juga dapat memberikan masalah yang terkait dengan kepedulian terhadap lingkungan seperti berikut.

Masalah: Salah satu pembaharuan penanganan limbah pabrik kertas PT. Pelaihari Pulp di Kabupaten Tanah Laut, daerah limbah dilokasikan pada sebidang tanah berbentuk persegi panjang yang lebarnya $80 \mathrm{~m}$ dan panjangnya $200 \mathrm{~m}$. Peraturan pemerintah daerah mensyaratkan bahwa daerah limbah paling sedikit memiliki luas $10.000 \mathrm{~m}^{2}$ dan memiliki zona pengamanan dengan lebar serba sama di sekeliling daerah limbah, seperti terlihat pada gambar.

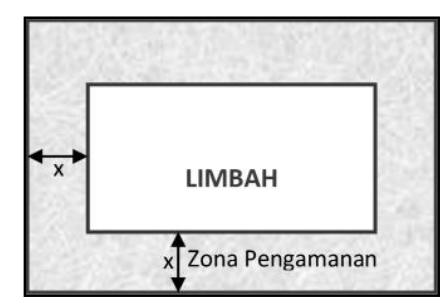


Berdasarkan peraturan pemerintah tersebut, pimpinan Pelaihari Pulp menetapkan realisasi luas daerah limbah adalah $10.800 \mathrm{~m}^{2}$. Dapatkah pembangunan daerah limbah tersebut direalisasikan pada tanah yang tersedia? Jika dapat direalisasikan, berapa ukuran daerah zona pengaman yang disediakan?

\section{Penyelesaian:}

Diketahui: Ukuran tanah yang tersedia $200 \mathrm{~m} \times 80 \mathrm{~m}$

Luas daerah limbah menurut peraturan pemerintah minimal $10.000 \mathrm{~m}^{2}$.

Kebijakan pimpinan Indo Rayon menetapkan luas daerah limbah $10.800 \mathrm{~m}^{2}$.

Ditanya: (a) Dapatkah pembangunan daerah limbah itu direalisasikan di atas tanah yang tersedia? (b) Berapa ukuran daerah limbah dan zona pengaman tersebut?

Interpretasi masalah dalam gambar sebagai berikut.



\section{Misalkan}

$p$ adalah panjang tanah yang tersedia

$l$ adalah lebar tanah yang tersedia

$p_{1}$ adalah panjang daerah limbah

$l_{1}$ adalah lebar daerah limbah

Berarti paling tidak ukuran daerah limbah

$p_{1}=p-2 x \quad$ dan $\quad l_{1}=l-2 x$

Menurut peraturan pemerintah luas daerah limbah minimal $10.000 \mathrm{~m}^{2}$ dan realisasi daerah limbah yang diinginkan $10.800 \mathrm{~m}^{2}$.

Karena daerah limbah berbentuk persegi panjang maka luas daerah limbah dapat dinyatakan

$$
\begin{aligned}
L_{1} & =p_{1} \times l_{1} \\
& =(p-2 x)(l-2 x) \\
& =p l-(2 p+2 l) x+4 x^{2}
\end{aligned}
$$

$$
\begin{aligned}
& 10.800=16.000-560 x+4 x^{2} \\
& 10.800=16.000-560 x+4 x^{2} \\
\Leftrightarrow & x^{2}-140 x+1.300=0 \\
\Leftrightarrow & x^{2}-10 x-130 x+1.300=0 \\
\Leftrightarrow & x(x-10)-130(x-10)=0 \\
\Leftrightarrow & (x-10)(x-130)=0 \\
\Leftrightarrow & (x-10)=0 \text { atau }(x-130)=0 \\
& \Rightarrow x=10 \text { atau } x=130
\end{aligned}
$$

Agar memperoleh luas daerah limbah yang diinginkan maka ukuran zona pengaman adalah $10 \mathrm{~m}$.

Berarti paling tidak ukuran daerah limbah

$$
\begin{array}{lll}
p_{1}=p-2 x & \text { dan } & l_{1}=l-2 x \\
p_{1}=200-2(10) & \text { dan } & l_{1}=80-2(10) \\
p_{1}=180 & \text { dan } & l_{1}=60
\end{array}
$$

Sehingga ukuran daerah limbah adalah $180 \mathrm{~m} \times 60 \mathrm{~m}$.

Jadi, daerah limbah di atas tanah yang tersedia dapat diwujudkan dengan ukuran daerah limbah $180 \mathrm{~m} \times 60 \mathrm{~m}$ dan ukuran lebar zona pengaman di sekeliling daerah limbah adalah $10 \mathrm{~m}$.

Masih banyak contoh dan konsep lain dalam pembelajaran matematika di sekolah yang bisa dikaitkan dengan pelestarian lingkungan. Secara umum, konsep dan aplikasi soal-soal matematika mengandung nilai-nilai (values) yang sangat berguna untuk pembentukan sikap dan kepribadian yang lengkap (utuh) termasuk pembentukan sikap peduli lingkungan. Di masa yang akan datang, sikap positif seperti ini semakin dibutuhkan karena semakin bertambah banyaknya kerusakan lingkungan, dan semakin banyaknya orang yang terkena akibat dari rusaknya lingkungan tersebut.

\section{Kesimpulan}

Pembelajaran matematika sebagai bagian dari kurikulum sekolah dapat memberi- 
kan sumbangan besar dalam upaya pendidikan karakter bangsa. Penerapan nilai-nilai matematika yang sesuai dengan kaidahkaidahnya dan diintegrasikan dengan realitas kehidupan sehari-hari seperti dikaitkan dengan isu lingkungan diharapkan mampu menjadikan siswa yang tidak hanya pandai matematika tetapi juga memiliki kepedulian terhadap lingkungannya. Sehingga, pembelajaran matematika akan mampu turut serta memberikan sumbangan positif dalam pengelolaan dan pelestarian lingkungan hidup.

Karakter positif yang dibangun melalui pembelajaran matematika yang dikaitkan dengan isu lingkungan tersebut memerlukan kreativitas guru. Setiap interaksi belajar mengajar baik konsep ataupun contoh permasalahan di upayakan untuk dikaitkan dengan nilai-nilai yang berwawasan lingkungan. Lingkungan yang terjaga akan menghindarkan bencana dan dapat dimanfaatkan untuk meningkatkan kesejahteraan manusia yang mengelolanya.

\section{Daftar Pustaka}

Hidayati, K., dkk. (2008). Implementasi Pembelajaran Matematika Berwawasan Lingkungan dengan Pendekatan Kooperatif Guna Mengembangkan Sikap Ramah Lingkungan dan Meningkatkan Hasil Belajar siswa. Pythagoras,4(1). http://journal.uny.ac.id/2015/01/20

Hobri. (2009). Model-model Pembelajaran Inovatif. Jember : Center for Society Studies

Hudojo, Herman. (2001). Pengembangan Kurikulum dan Pembelajaran Matematika. Universitas Negeri Malang.

Rijal Wahid Muharram, Muhammad. (2012). Quantum Mathematic, Memahami Nilai-Nilai Matematika untuk Membangun Karakter Bangsa. Universitas Pendidikan Indonesia. Prosiding. http://eprints.uny.ac.id/8515/1/P\%20\% 2063.pdf/2013/05/10.
Streefland, L. 1991. Realistic Mathematics Education In Primary School. Utreecht: Center for Science and Mathematics Education, Netherlands.

TIM MKPBM. (2001). Strategi Pembelajaran Matematika Kontemporer. Universitas Pendidikan Indonesia.

Walle, Van De. (2008). Matematika Sekolah Dasar dan Menengah Pengembangan Pengajaran. Erlangga.

Yohanes, Rudi Santoso. (2011).Kontribusi Pendidikan Matematika dalam Pembentukan Karakter Siswa. Prosiding Seminar Nasional dan Pendidikan Matematika. Universitas negeri Yogyakarta.

Yusuf, M. (2000). Pendidikan Kependudukan \& Etika Lingkungan. Yogyakarta: Lembaga Studi dan Inovasi Pendidikan. 